\title{
Los primeros pasos en el escorzo de la figura humana. Un análisis desde la geometría
}

\section{The first steps in the foreshortening of human figure. A geometrical analysis}

\author{
M. Ángel Maure-Rubio \\ Universidad Complutense de Madrid \\ maure_ma@art.ucm.es
}

Recibido: 17 de febrero de 2015

Aprobado: 9 de julio de 2015

\section{Resumen}

A través de un recorrido histórico centrado en el Renacimiento, se exponen las aportaciones más significativas de teóricos y artistas en la evolución del escorzo de la figura humana desde un punto de vista geométrico.

Los artistas que con sus dibujos y escritos ayudaban a otros en el aprendizaje de la representación, se apresuraron a incluir el estudio del escorzo en sus tratados, buscando métodos que facilitaran su dibujo sobre cualquier soporte y en cualquier posición en el espacio.

En este artículo se analizan y enlazan los trazados propuestos por los estudiosos de la geometría, con las obras de arte que reflejan importantes avances en este sentido.

Soportes como el lienzo, el muro o la bóveda, presentan al pintor superficies diferentes de trabajo y en distintas posiciones en el espacio. La figura humana, protagonista en la escena, tendrá que adaptarse a ellos para ser contemplada desde unos espacios arquitectónicos cada vez más amplios y con más posibilidades.

Fue necesario dominar la perspectiva en la pintura, y muy particularmente en la mural, para ofrecer composiciones cada día más ambiciosas y sorprendentes.

Palabras clave: perspectiva, pintura, geometría en el arte, pintura mural, dibujo.

Maure-Rubio, M.A. (2016): Los primeros pasos en el escorzo de la figura humana. Un análisis desde la geometría. Arte, Individuo y Sociedad, 28(2) 253-275

\footnotetext{
Abstract

Through a historic path centered in the Renascence, are exposed some of the most meaningful contributions of theorist and artists the evolution of the human figure foreshortening from a geometrical involving point of view.

The artist, using their drawings and texts to help others in the learning of the representation, rushed to include the study of the foreshortening in their treatises, searching ways to facilitate its drawing in any kind of support and any position in space.

In this article are analyzed and linked, treatises of geometrical experts, with art works that reflect important advances in this field.

Supports such as canvas, walls or vaults represent new working surfaces and different space positions for the artist. The human figure, protagonist in the scene, will have to adapt in order to be contemplated from wider and different architectonic spaces.

It was necessary to master perspective in drawing, and more specifically in walldrawing, in order to offer compositions that were each time more ambitions and surprising. Keywords: perspective, painting, geometry and art, mural painting, drawing. 
Sumario: 1. Introducción, 2. La búsqueda de un procedimiento sistemático para el escorzo, 3. El dibujo de una geometría asociada a la forma, 3.1. El término "quadratura" en la Región Lombarda, 4. Caminos nuevos, y repetidos, en la representación del escorzo, 5. La figura en escorzo, pintada sobre un soporte vertical, 6. La figura en escorzo, pintada sobre la superficie de transición entre el muro y el techo, 7. La figura en escorzo, pintada sobre el techo plano, o la superficie abovedada. Referencias. Notas.

\section{Introducción}

La figura humana se aprendía a dibujar en los talleres, siguiendo todo un proceso bien descrito por los propios artistas, que arrancaba con el estudio de la geometría euclidiana, para continuar a partir del Renacimiento con el de la perspectiva, tal y como afirmaba Leonardo da Vinci (1452-1519): "El joven debe empezar por aprender la perspectiva;..." (Da Vinci, 2001: 90).

Tras ésta, el aprendiz continuaba con el estudio de la anatomía y proporción, y practicaba copiando los dibujos o "cartillas" del maestro, y dibujando modelos de yeso, y reales. Siempre era mejor buscar el modelo natural, que copiar los dibujos del maestro porque como de nuevo señala Leonardo:

... es más seguro ir derechamente a los objetos que nos ofrece la naturaleza, antes que a las imitaciones que los empeoran y que nos inculcarían hábitos mezquinos. Porque no hay que beber de vaso cuando se puede ir a la fuente. (Da Vinci, 2001: 91).

Esta labor realizada en los talleres, y entrado el s. XV también en las academias, se complementaba para los escorzos con el dibujo de esculturas y mediante la copia de las posturas impuestas a maniquíes de madera, cera, o metálicos.

El escorzo así practicado se incorporaba a los escenarios pintados poco a poco, mediante figuras aisladas introducidas en pequeños grupos en las grandes composiciones, tal y como Leonardo en su tratado de la Pintura aconseja:

Cuando se haya de pintar una sola figura, se debe procurar evitar los escorzos tanto en las partes de ella, como en el todo (...) Pero en las historias de muchas figuras se harán siempre que ocurra, especialmente en las batallas, en donde precisamente ha de haber escorzos y actitudes extraordinarias entre los sugetos del asunto (Da Vinci, 1985: 43).

La introducción de las figuras en escorzo en la pintura y muy especialmente en la mural, fue imparable, pues conforme la arquitectura desarrollaba mayores espacios diáfanos, las iglesias, palacios y villas ofrecían mayores superficies en muros, bóvedas y cúpulas, que los pintores de frescos aprovecharon para plantear nuevos retos, creando escenarios en los que, arquitectura, escultura y pintura se unían y confundían en un grandioso espectáculo.

Y fue entonces cuando los artistas estudiosos de la geometría, como veremos a continuación, empezaron a incluir en sus tratados, capítulos dedicados al dibujo del escorzo de la figura humana, buscando métodos que facilitaran su representación en perspectiva. 


\section{La búsqueda de un procedimiento sistemático para el escorzo}

La aplicación de la perspectiva al dibujo de la figura humana, estableciendo un procedimiento sistemático para ello, se debe a Piero della Francesca (1415-1492), quien en torno a 1474 escribe bajo el título en latín De prospectiva pingendi, un tratado de perspectiva que quería hacer llegar a los artistas.

En él, mediante textos y figuras, difundió sus extraordinarios conocimientos de esta ciencia, y mostró a los pintores cómo representar sólidos de complejidad creciente, hasta llegar al escorzo de la figura humana construido por puntos.

En el libro III del tratado, se propuso representar la perspectiva del rostro en cualquier posición mediante un método preciso, sin preocuparse del trabajo y tiempo que pudiera llevar su dibujo. Para ello seccionó la cabeza mediante planos paralelos a un hipotético plano horizontal, obteniendo diferentes contornos al unir una serie de puntos que Piero numeró y posicionó tanto en planta como en la vista de perfil, utilizando proyecciones cilíndricas ortogonales como más adelante haría Alberto Durero (1471-1528)

A partir de las dos vistas, situó el plano de proyección o plano del cuadro y la posición del espectador respecto del conjunto, y obtuvo la intersección entre dicho plano y los rayos visuales que miran a cada uno de los puntos señalados. Este proceso lo llevó a cabo en dos escenarios: el que contemplaba todo visto en planta, y el que lo hacía mirando todo de perfil.

En una segunda etapa, situando los puntos recogidos en el plano del cuadro en planta a modo de abscisas, y los puntos recogidos en el plano de perfil como ordenadas, Piero obtuvo la posición de cada uno de ellos en perspectiva, sin más que dibujar sus coordenadas. (Piero,1984:Tav. XLI- XLIV). (Fig.1A)

El procedimiento podía extenderse a toda la figura humana, o a cualquier otra forma por muy compleja que fuera.

El fresco situado en la llamada Sala della Resurrezione en el Palacio medieval de la Residencia, hoy Museo Cívico de Sansepolcro, fue pintado por Piero en torno a 1460. El soldado dormido situado de frente, que la tradición identifica con su autorretrato, tiene la misma disposición de la cabeza que la representación en perspectiva que acabamos de describir (Fig.1B).

Si las fechas de ejecución de la pintura y las de redacción del tratado, no nos engañan, parece que Piero realiza el mural antes que el estudio de su rostro en perspectiva, pero sería razonable considerar, que su método lo hubiera aplicado con anterioridad al dibujo del mural, llevándolo después al tratado.

Ni antes ni después, se expondría un procedimiento razonado, que mostrara como dibujar la perspectiva de una parte de la figura humana con tanta precisión. Piero vio que la forma del rostro no admitía simplificaciones si se quería realizar de una manera científica, y que las pautas seguidas constituían un método que podría aplicarse para representar cualquier otra figura.

El lento camino a seguir, se justifica, porque lo que obtenemos son precisamente los puntos de una superficie irregular, como ocurre aplicando otros procesos, en la escultura, o en la representación del terreno en topografía, donde podemos obtener tantos puntos como deseemos, para una mayor o menor precisión. 
A este procedimiento Piero le dedicó muchos dibujos y explicaciones, empezando por representar figuras geométricas, que no requerían ser seccionadas al quedar definidas por sus vértices y aristas. Es la Costruzione legittima, que hoy conocemos como Método directo, y cuyos principios no han cambiado ${ }^{1}$

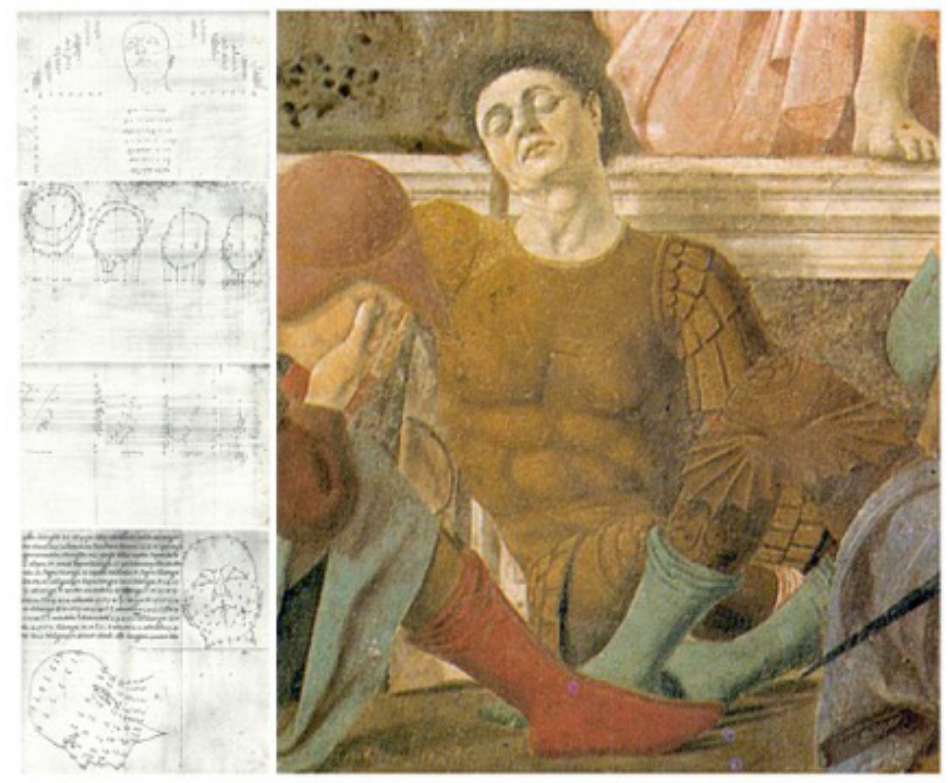

Figura 1A. Tav. XLI- XLIV del tratado De prospectiva pingendi con el procedimiento Costruzione legittima. (Extraída del tratado original).

Figura 1B. Detalle de "La resurrección de Cristo". Museo Cívico de Sansepolcro.

(Disponible en https://upload.wikimedia.org/wikipedia/commons/c/c2/Resurrection.JPG).

Pero la obtención del escorzo por este procedimiento, era poco práctico para el pintor, por eso los artistas siguieron investigando otros métodos. Así hizo Alberto Durero, trabajando casi de manera simultánea en dos manuscritos a la vez. Underweysung der Messung publicado en 1525 ( $1^{\text {a }}$ edición), -donde muestra la manera de medir y propone nuevos procedimientos para el dibujo en perspectiva- y De symmetria partium in rectis formis humanorum corporum, finalizado en $1523 \mathrm{y}$ llevado a la imprenta con posterioridad al anterior, en el que analiza las proporciones del cuerpo humano y plantea otro procedimiento para su dibujo.

En cada Tratado, Durero abordó el escorzo de manera diferente. En la primera edición de Underweysung, lo obtiene recurriendo a dos dispositivos cuya construcción y funcionamiento nos presenta, y que ilustra con los dibujantes que los utilizan, el primero, un "retratista" y el segundo el conocido como el del "laúd" (Fig.2A). Ambos dispositivos permitían el dibujo en perspectiva con total precisión pues en definitiva materializaban los principios de esta ciencia sin necesidad de tener conocimientos de ella, por eso Durero habla de copiar y no de dibujar en perspectiva. "Si quieres copiar lo que ves delante de ti, prepara antes un dispositivo adecuado." (Durero, 2000: 326). 
Nos fijamos en el dispositivo del "laúd", quizás el único inventado por él.

La explicación de su funcionamiento es exhaustiva. Observamos que el procedimiento de ejecución del dibujo es laborioso, pues traslada el contorno y lo más representativo del objeto al plano del dibujo, "punto a punto", necesitando la ayuda de un compañero.

En una segunda edición ampliada y publicada en 1538 tras su muerte, Durero introdujo dos dispositivos diferentes, ilustrados por el "dibujante de una jarra" y por "la mujer desnuda" (Fig.2B). Este último, ya conocido por algunos artistas, incorporaba un bastidor vertical, que se podía acercar o alejar de la figura a dibujar, y sobre el que se tensa una retícula de hilo. Por lo que "Permite representar cada cuerpo al tamaño requerido, más grande o más pequeño (...) Es preciso para ello un marco con un mallado de hilo negro y sólido,..." (Durero, 2000: 335). Y además:

Item si alguno desea, a partir de una pequeña imagen, pintar un gigante sobre la pared (...) no hagas una gran cuadrícula en papel, sino que recorta grandes cuadrados de papel del tamaño de los que deberán tener los recuadros de la cuadrícula. (Durero, 2000: $336)$.

El procedimiento de la retícula, fue utilizado durante siglos por los pintores para trasladar los bocetos al muro. Realizado el boceto sobre un soporte que incluyera una retícula, y escalada ésta al tamaño del mural, permitía al artista trasladar malla y boceto sin perder la proporción del conjunto. La novedad fue que con el dispositivo ingeniado por Durero se podía dibujar con precisión el difícil escorzo, y es muy posible que esta utilidad fuera también empleada por los fresquistas como paso previo a la representación sobre el muro, cumpliendo así el doble objetivo que señaló con precisión su inventor.

\section{El dibujo de una geometría asociada a la forma}

Con la intención de ofrecer otras alternativas al artista, Durero en el libro III y IV de su Tratado De symmetria de 1528, describió e ilustró otro procedimiento muy diferente, en el que no se utilizaba ningún dispositivo. (Durero, 1557:78-120).

Para ello vinculó las formas del cuerpo humano y los sólidos geométricos, entendiendo que sería más fácil dibujar el escorzo a partir de ellos.

Centró sus esfuerzos en el dibujo de la cabeza, como hiciera Piero, inscribiéndola en un prisma cuyas caras dividiría en nueve espacios horizontales y siete verticales a través de líneas paralelas. La retícula formada serviría para trasladar los rasgos más importantes a las diferentes vistas.

Durero pudo basarse en el manuscrito De Pictura (1435) de L.B.Alberti (14041472), donde se describe como dibujar un círculo ayudándose de una retícula trazada en un rectángulo. El círculo dibujado sobre la retícula, encontraría puntos de intersección con ella que facilitarían su representación en perspectiva (Alberti, 1999: 97).

Dibujó la cabeza frontalmente y también girada entorno a un solo eje perpendicular o paralelo al papel, y para indicar como representarla cuando adopta cualquier otra 
postura, traza los prismas sin figura en su interior, descomponiendo el movimiento final en la suma de dos giros. (Fig.2C, D)

Durero sabía que las vistas obtenidas, al usar proyecciones cilíndricas, se alejaban del escorzo (perspectiva), pero dio prioridad a la sencillez del método propuesto, entendiendo que en la representación de la cabeza el resultado del dibujo sería muy similar.

Este procedimiento lo extiende al resto del cuerpo humano, pero solo lo ilustra con alguna figura erguida y frontal, en la que cabeza, cuerpo y miembros se inscriben en superficies prismáticas. (Fig.2E).
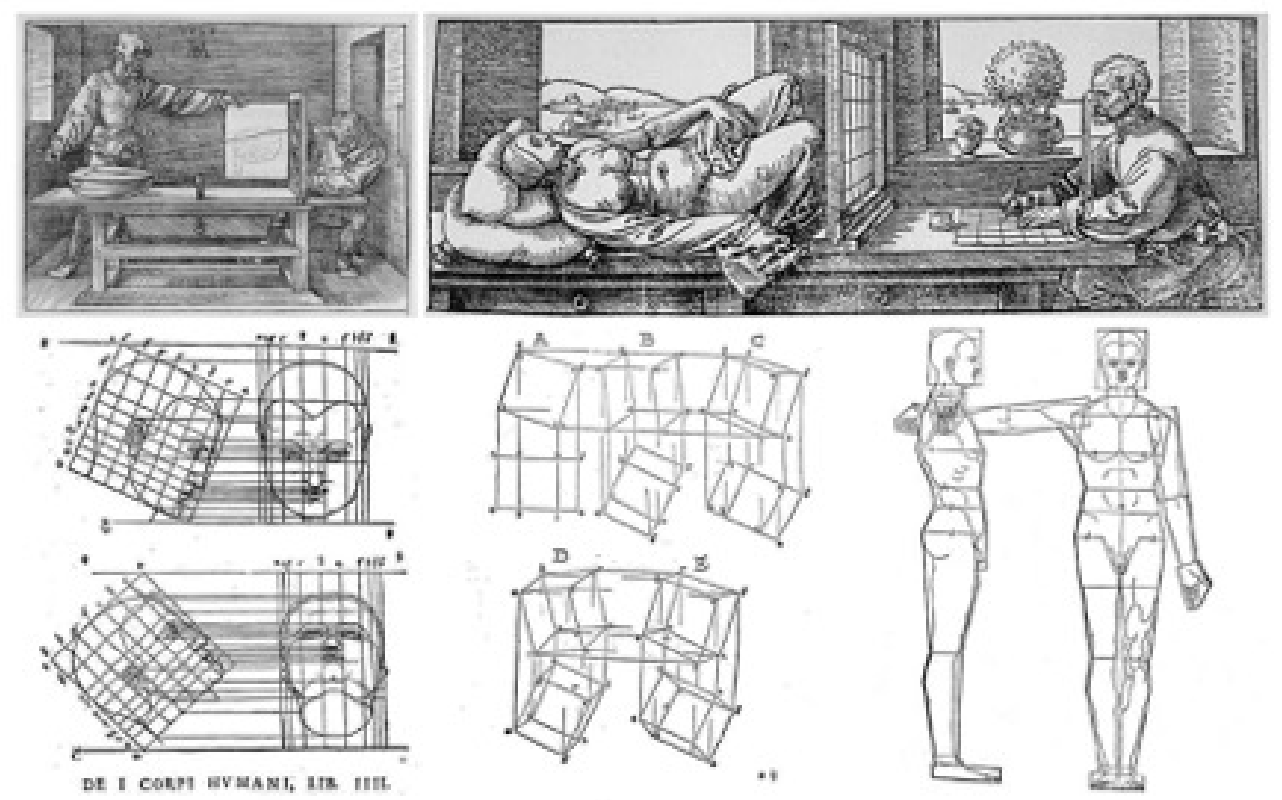

Figura 2A. Underweysung. El dispositivo del "laúd". Figura 2B. Underweysung de 1538. Dispositivo ilustrado por "la mujer desnuda". Figura 2C. De symmetria. Proyecciones de la cabeza girada entorno a un solo eje. Figura 2D. Proyecciones del prisma sin figura en su interior, como suma de dos giros.

Figura 2E. Figura inscrita en prismas. (Todas las figuras han sido extraídas del tratado original).

Pero también Durero pudo encontrar sus fuentes en los textos y obras de la antigüedad. Las formas geométricas asociadas a la figura humana arrancaron con las primeras manifestaciones artísticas, con especial protagonismo en Grecia donde artistas como Lisipo (370-318 a.C.) y filósofos como Pitágoras (569-475 a.c.) y Platón (427-347 a.c.)_miraban el cosmos para interpretar sus relaciones armónicas y recogerlas en sus obras. El círculo o el cuadrado ayudaron a establecer el encaje y las proporciones en la figura humana. El homo quadratus de Vitruvio, inscrito en un círculo, cuya altura es igual a su anchura (con las manos extendidas), fue punto de partida del estudio de las proporciones en el hombre y en sus obras. 
Luego si la Naturaleza dispuso el cuerpo del hombre de tal manera que se correspondan las proporciones de cada miembro con el todo, con razón quisieron los antiguos que existiera también en las obras perfectas esa misma correspondencia de medidas con la obra entera. (Vitruvio 1980:68).

Los escultores dieron el paso del plano al espacio, al trasladar los dibujos de las vistas frontales y de perfil a los planos o caras de los bloques prismáticos de piedra para extraer los correspondientes volúmenes sobrantes.

En el siglo XIII, - una época en la que parecía que las artes del dibujo y de la pintura se hubieran olvidado del camino emprendido en el pasado- sabemos sin embargo, gracias al Cuaderno de apuntes de Villard de Honnecourt (s.XIII), que triángulos, cuadrados y polígonos en general, se siguieron empleando como esquemas para encajar, enmarcar o descomponer las figuras de animales, plantas o personas. En el dorso de la hoja 19, Villard utiliza la trama de cuadrados y sus diagonales tanto para encajar un rostro, como para representar un grupo de figuras. Rectas y geometrías sencillas, en otros dibujos se asocian a giros y simetrías para expresar movimiento. Numerosos ejemplos ocupan las hojas 18,19 (ambas caras) del Cuaderno y el dorso de la 21. Villard, un "arquitecto" viajero que tomaba notas y hacía dibujos en sus desplazamientos de trabajo, en el dorso de la hoja 18 dejó escrito: "Aquí comienza el método de los dibujos del retrato, tal y como el arte de la geometría lo enseña para trabajar con soltura"(Honnecourt 1991: 134).

Villard no perseguía el dibujo del volumen; utilizaba la geometría para encajar y proporcionar las figuras en el plano. Y en esta línea aún aparecieron tratados como $D e$ Sculpture (1504) donde Pomponio Gaurico (1480?-1530), un "broncista" pero sobre todo un "humanista", tampoco aportó nada nuevo respecto al dibujo del escorzo.

Gaurico vuelve a recordarnos, en un capítulo dedicado a las proporciones (De Symmetria), como utilizar, rectas y polígonos sencillos, para dar forma al boceto, al dibujo que encaja la figura. Llamaba lineamenta:

...al trazado adecuado de las líneas que contribuyen a dar forma a un objeto cualquiera. Hay unas líneas exteriores, llamadas contornos cuando rodean los bordes; otras son líneas internas, cuando queremos señalar las partes interiores y distinguir las articulaciones de los miembros"..."Podría pasar toda esta jornada estival hablando de cómo algunos enseñan a enmarcar un rostro demasiado demacrado en un triángulo, y otro bastante relleno en un cuadrado,... (Gaurico 1989: 133-134).

Este Tratado -que se presenta como un diálogo escrito dirigido a un público culto al que se pretende enseñar los principios de la escultura- y que como vemos no contempla "el escorzo", tiene sin embargo aportaciones fundamentales sobre la proporción desarrolladas en el Capítulo II, tan importantes, que Durero las utilizó para escribir su correspondiente capítulo sobre la proporción en De symmetria (1528), como señala Weixlgaärtner (Gaurico 1989: 86).

Años más tarde aparecen los tratados de Durero, que hemos comentado, inician el salto a la representación del volumen, del escorzo, bajo formas geométricas. Estos estudios tuvieron continuidad en la figura de Erhard Schön (1491-1542), ${ }^{2}$ un posible discípulo suyo que publicó el tratado Unnderweissung der Proportzion en 
Nuremberg (1540), demostrando que los cubos y prismas eran eficaces para dibujar no solo la cabeza, sino toda la figura, sin deformarse y en cualquier posición. Sus dibujos unieron la proporción vitruviana y la simplificación de la forma.

Inició el proceso con el escorzo de la cabeza. Dibujó para ello su vista lateral encerrando el rostro en un cuadrado que descompone en otros nueve para formar una retícula que recogiera los rasgos más significativos.

El cuadrado inicial deja fuera, la nariz y el cuero cabelludo, como también encontramos en un dibujo de los estudios anatómicos de Leonardo de 1488 y en otros tratados posteriores como el de Arfe de 1585.

De la planta y la vista lateral asociada al cuadrado, pasó a la representación del volumen asociado al cubo, con ejemplos de cabeza y hombros en distintas posiciones.

En estos ejemplos vemos como Schön ilustra un proceso lineal en el que el cubo se va diluyendo para dejar paso a la figura que encierra, mostrando así la eficacia y rapidez de su procedimiento.

Para aplicarlo al dibujo de la figura completa, traza un Homo quadratus basado en el de Vitruvio, y establece en él proporciones [rostro (1), cuello (0.5), cuerpo (3) y extremidades (4.5)] que traslada a los volúmenes cúbicos, prismáticos, o piramidales con los que realizar todo tipo de escorzos. (Schön, 1540: 4) (Fig.3A)

Para situar y no perder la proporción en sus figuras utilizaría el plano del suelo, el enlosado o cuadricula a la manera de Alberti, posicionándolas correctamente y con rapidez, y disminuyendo su tamaño en razón a la distancia al espectador. Para comparar unas con otras y revisar las reglas de la correcta perspectiva, las dibujó en grupo y en distintos escorzos, tal y como en la práctica las debían representar los pintores.

Tomamos como ejemplo una de sus xilografías, en la que vemos sobre un enlosado en perspectiva central, a distintos personajes en diferentes escorzos haciendo uso de las aportaciones descritas. (Schön, 1540:18) (Fig.3C).

\subsection{El término "quadratura" en la Región Lombarda}

El Quadraturismo fue el arte de crear arquitectura ilusionista a partir del Quattrocento en Italia. De ahí la expresión quadratura empleada para definir las pinturas de arquitecturas y decoraciones fingidas realizadas en los muros o techos con la intención de prolongar artificialmente el espacio real. Sabemos que en los siglos XVII y XVIII llego a ser una especialización que practicaban los pintores con grandes conocimientos de perspectiva llamados quadraturisti.

Sin embargo el término quadratura tuvo a mediados del siglo XV otro significado en la región de Lombardía, donde en ciudades como Milán o Brescia, el artista se inclinó, como señala Giulio Bora, por "... una formulación fundamentalmente esquemática y regularizada de las figuras..." (Bora, 1999:14).

Fue el pintor milanés Giovanni Paolo Lomazzo (1538-1600) quien estableció el hilo conductor de esta expresión cuando en su tratado Idea del tempio della pittura de 1571, hace referencia a Lisipo, al magisterio con el que realizaba la "...quadratura de la nariz y de todos los otros miembros, con suma armonía...", añadiendo que el Trattato di quadrature escrito por Lisipo y hoy perdido, enseñó a realizar las 
quadrature del cuerpo humano a otros artistas. Según Lomazzo las quadrature antiguas eran imitadas por artistas como Miguel Ángel y Rafael. (Lomazzo.1590:15).

En este último punto, Lomazzo se refiere a la vuelta al canon antiguo de proporciones establecido para la figura humana por Mirón, Policleto, Fidias, o Lisipo. Un artista español, Arfe y Villafañe (1535-1603), contemporáneo de Lomazzo, en su tratado de 1585 De varia commensuración para la Esculptura y Architectura que citaremos después, resume y simplifica las grandes y pequeñas modificaciones a las que estuvo sujeto el canon de proporciones, tomando como módulo, el rostro que “...se forma en un quadrado (...) Todo el rostro viene a ser tan ancho como largo, contado desde la punta del cabello hasta el extremo de la barba, y la superficie de la cabeza sube un tercio más..." (Arfe 1773: 96-97).

Arfe escribió, que para los grandes escultores griegos la proporción del hombre "bien dispuesto" era la Quincupla, que fijaba el ancho del cuerpo en dos rostros y la altura en diez. Añadiendo que esta medida fue durante mucho tiempo alterada por otra, que acortaba un rostro la altura total y que fijaron Pomponio Gaurico y Alberto Durero.

La gran difusión de los tratados de Durero propició que algunos artistas siguieran estas nuevas pautas, hasta que en Italia escultores y pintores famosos como Mantegna, Rafael o Miguel Ángel “...bolvieron a resucitar esta Simetría, y proporción que los antiguos habían usado...”.

Arfe concluye señalando, que este criterio fue introducido también en España por Alonso Berruguete y Gaspar Becerra, a través de sus obras y enseñanzas. (Arfe 1773: 94,95).

El hilo conductor que había establecido Lomazzo continúa -en este su primer Tratado- atribuyendo a Donato Bramante (1443-1514) y a Vicenzo Foppa (14301515), la reinvención de este procedimiento geométrico. El primero, dibujó las quadrature del cuerpo humano y el segundo, escribió sobre las quadrature de membri del corpo umano e del caballo.

Trece años más tarde, Lomazzo en su obra Trattato dell'arte della pittura, scoltura, et architettura (1584), vuelve a atribuir a Foppa el dibujo de figuras quadrate, señalando que éste pudo haberse inspirado en la obra de Lisipo, y añadiendo que también Bramante continuó este camino al dibujar varias de ellas en un libro que según parece acabó en las manos de Luca Cambiaso. (Lomazzo 1585: 320).

$\mathrm{Y}$ es entonces cuando el término quadratura retomado por estos artistas y asociado al sentido geométrico de cuadrar, encajar, y componer buscando la proporción armónica del conjunto, revela una dimensión volumétrica. La representación de la figura humana en escorzo requería la descomposición de los volúmenes no en cuadrados, sino en cubos prismas y pirámides, y parece que así fueron los dibujos de Bramante que inspiraron a Cambiaso.

Pudiera ser que todo este recorrido del término "quadratura" que Lomazzo recoge en sus dos Tratados, tuviera como fin, explicar la forma de trabajar de Luca Cambiaso (1527-1585), de quien dice que era capaz con su felice mano, de dibujar las quadrature de los miembros de las figuras con sus contornos proporcionados, ofreciendo "...todo lo que con este arte se podía mostrar; porque lo que era difícil e imposible de expresar para otros, para él era fácil y sencillo." (Lomazzo 1585:384). 
Pero Cambiaso pudo disponer también de alguna de las reimpresiones del tratado de Edward Schön, cuyos grabados ofrecen esquemas volumétricos muy similares a sus dibujos preparatorios.

Este pintor genovés, durante años, había demostrado sobradamente su dominio de la línea y el trazo en la búsqueda del escorzo y el movimiento. Guerreros, caballos y gigantes, llenan los dibujos preparatorios de las pinturas murales que realizó en iglesias y palacios de su ciudad trabajando junto a su padre Juan.

Pero en torno a 1560 se produjo un cambio hacia la geometrización de las figuras en la elaboración de dichos dibujos preparatorios. Algunos investigadores afirman que fue el padre de Luca quién inició esta simplificación prismática.

Fuera cual fuera la referencia de este cambio, Cambiaso era capaz de organizar el espacio con sus figuras en movimiento, tras armonizar sus líneas y proporcionar sus volúmenes geométricos.

En el museo de arte de la Universidad de Princeton se conserva un valioso ejemplo; es el boceto del retorno de Ulises realizado en 1565 para la pintura al fresco, situada en el techo del salón que lleva su nombre, del Palacio Gerolamo Grimaldi de Génova (Fig.3B). En él los personajes adoptan atrevidos escorzos en una correcta perspectiva, con posturas equilibradas incluso en movimiento. La geometría se impuso en sus dibujos y desde entonces sus trazados preparatorios muestran una mejor ordenación del escenario inventado. Su traslado al fresco del salón mantuvo, el vigor, la energía y el movimiento del boceto, y sus figuras, aún cubistas, dominan la escena de esta obra, toda ella enmarcada como si de un cuadro se tratase a los ojos del espectador. (Fig.3D)

Finalmente Cambiaso, fue llamado por Felipe II para decorar el Escorial junto a su hijo Horacio, y trabajó en el Monasterio hasta el final de su vida. Sus estudios preparatorios, sirvieron de modelo e inspiración para otros artistas y se encuentran hoy en diversos museos del mundo, siendo el mejor ejemplo de aplicación de las quadrature a la representación del escorzo en la pintura.

Tras la fotografía y en el nuevo espacio aperspectivo, el cubismo y las vanguardias del siglo XX retomarían este proceso de simplificación geométrica del escorzo con intenciones muy diferentes. Una de ellas, interpretar la figura humana, no reproducirla. A las formas simples y a las poliédricas se añadirían conos, esferas y cilindros (Cezanne), con un nuevo tratamiento del espacio pictórico, en el que se situarían artistas como Picasso (Tres mujeres 1908), Fernand Léger (La zurcidora 1910, La Escalera 1914), Francis Picabia (La Procesión en Sevilla 1912) o De Chirico (El profeta 1915), entre otros. 

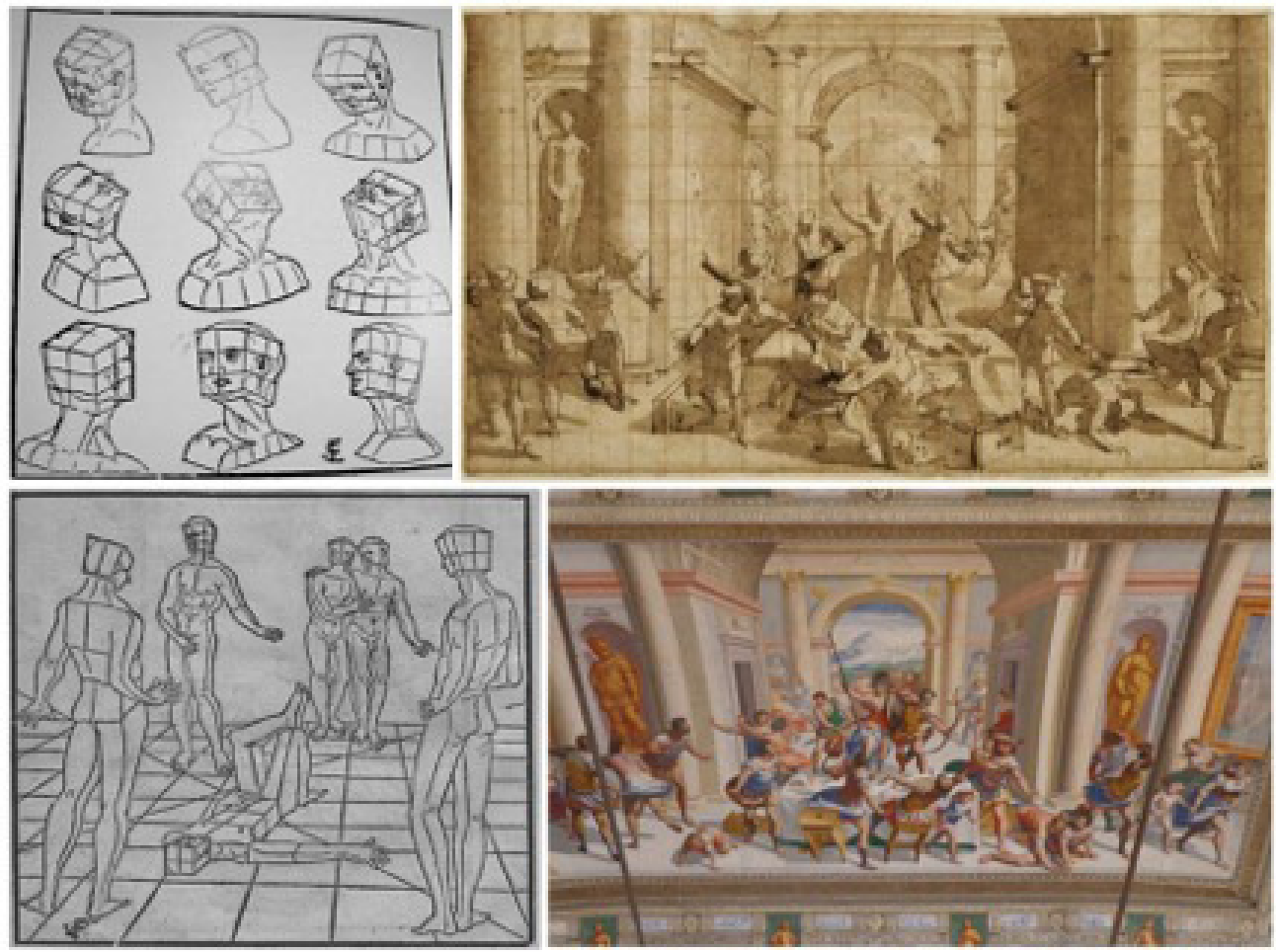

Figura 3A. Unnderweissung der Proportzion. Simplificación, folio 4. (Extraída del tratado original). Figura 3B. Boceto del "Retorno de Ulises". Museo de arte. Universidad de Princeton. (Photo Bruce M. White. Courtesy of the Princeton University Art Museum). Figura 3C. Unnderweissung der Proportzion. Figuras en perspectiva sobre enlosado, folio 18. (Extraída del tratado original). Figura 3D Techo del Salón Cambiaso. Palacio Gerolamo Grimaldi. Génova. (Disponible en: https://upload. wikimedia.org/wikipedia/commons/9/98/Palazzo_della_Meridiana_Salone_Cambiaso_Affresco_ Ulisse.JPG).

\section{Caminos nuevos, y repetidos, en la representación del escorzo}

El uso de prismas envolventes para el dibujo de la figura humana, alternó con otros procedimientos para representar el escorzo. Un manuscrito, hoy conservado en la Morgan Library de Nueva York, volvería a ilustrar, con este fin, los principios fundamentales del dibujo en perspectiva. Se trata del Códice Huygens, reunido en 1560-70 por Carlo Urbino (1520?-1585) para recoger el pensamiento y las ideas de Leonardo da Vinci. En este manuscrito compuesto por cinco libros, tanto el material gráfico, obra de Urbino, como el texto, giran en torno a la representación de la figura humana.

El último de ellos, que se denominó la Prospettiva delle Regole del Disegno, desarrolla un procedimiento muy alejado de la abstracción geométrica. Urbino obtuvo la perspectiva de cada una de las figuras que dibujó en los folios del códice, proyectando los puntos más representativos sobre un arco de circunferencia, que con 
centro en el ojo del espectador que dibuja, pasa por algún punto concreto de la figura a representar. En el folio 115, el punto elegido es la rodilla apoyada en el suelo. Por él trazaría los dos arcos de circunferencia desde los dos puntos de vista cuyos resultados compara (Fig.4A).

Hizo muchos bocetos en los que tanto la figura a representar, como el espectador, ocupan posiciones diferentes, y dibujó a partir de este procedimiento los correspondientes escorzos. De esta manera podemos comparar los resultados y asociar lo que miramos y desde donde lo hacemos, con lo que finalmente dibuja en perspectiva. Si midiéramos la longitud de los arcos limitados por los diferentes puntos de las figuras proyectadas sobre ellos, comprobaríamos que los correspondientes escorzos dibujados, responden a dichas magnitudes de manera aproximada. Es verdad que se inventa la dimensión transversal de los mismos, pero ello no impide que su procedimiento se entienda, aunque lo aplique solamente en una dirección del espacio.

Al situar Urbino una línea del horizonte por la que se desplaza el ojo de quien observa, acercándose o alejándose de la figura a representar, vemos claramente su incidencia en el ángulo visual -que dibuja- y las alteraciones que produce este movimiento en la forma y posición de los correspondientes escorzos. Esta singularidad en la descripción de los dibujos, que nos permite comparar los resultados obtenidos, hace que el Códice tuviera un gran valor pedagógico.

Otros estudiosos de la geometría no se plantearon nuevos caminos para la representación del escorzo y recurrieron una y otra vez, a lo que ya había claramente expuesto Durero en su Tratado De symmetria, incluso copiando sus ilustraciones. Esto fue lo que hizo el eminente tratadista multifacético, Daniele Barbaro (15141570) en La pratica della perspettiva de 1568, donde en el apartado octavo y al tratar sobre la medida del cuerpo humano, utilizó figuras de los tratados de Piero y Durero, sin aportar ninguna novedad. (Barbaro.1569:181)

Pero no siempre fue así, pues la influencia de los tratados de Durero dio lugar a otros estudios que ampliaron el conocimiento de la figura humana para su mejor representación. Este es el caso del tratado De varia commensuración para la Esculptura y Architectura, publicado en 1585 por el orfebre español, ya citado, Juan de Arfe y Villafañe mientras realizaba la Custodia en plata de la catedral de Sevilla (1580-87). Su importancia radicó en que fue el primero de Anatomía para artistas, al presentar el análisis y dibujo de los músculos del cuerpo humano.

En el Título IV de su segundo libro, Arfe mostró como dibujar lo que el entendía como "escorzo" del cuerpo humano (Arfe, 1773:172-187). Sus explicaciones, muy detalladas, se concretaron solo en la representación de la cabeza, brazos y piernas, en posiciones en general frontales o laterales. Arfe utilizó en sus ilustraciones, proyecciones cilíndricas ortogonales para completar las vistas. Era totalmente consciente de que tanto él como Durero no dibujaban en perspectiva, es decir en escorzo real.

Para que quedara claro que no ignoraba las reglas de la geometría, la siguiente cita con "rima", puntualiza que el "escorzo" -según su criterio- era precisamente el que se hacía con proyecciones cilíndricas, diferenciándolo de la propia representación en perspectiva: 
El escorzo es razón demostrativa para mostrar relieve en lo que hacemos.

Es semejante en algo a la perspectiva aunque por paralelas lo guiemos.

Será demostración afirmativa y muy precisa esta que ponemos.

La cual nos escribió y hallo primero el milagroso ingenio de Durero (Arfe, 1773:172).

Otro gran texto de anatomía artística que maneja también las proyecciones ortogonales y no la perspectiva, es el Livre de Pourtraicture escrito en Francia por Jean Cousin (1522-1594), pintor e hijo de un gran artista y geómetra con el mismo nombre, que en 1560 publicó el Livre de perspective. (Cousin. 1560)

El Livre de Pourtraicture que podríamos traducir, como el "Libro del trazado de la figura", fue anunciado por su padre como un complemento al suyo. Se duda de su fecha de publicación, siendo la más probable la de 1571 con reediciones en el siglo XVII como la que sirve de referencia a este texto.

Sus dibujos siempre se ilustran con la explicación de su trazado, y su aportación al "escorzo", entendido a la manera de Durero, es decir mediante proyecciones cilíndricas, es muy significativa (Fig.4B).

Cousin no utilizaba los prismas envolventes de la figura para simplificar su dibujo, sencillamente aplicaba a los rasgos más significativos la correspondencia entre vistas. Bastaba con situar la planta y el perfil de la figura completa, en la posición adecuada y aplicar el esquema de transferencia inventado por Durero (Durero. 1557: 22r), para obtener la tercer vista en "escorzo". (Cousin.1656:35) (Fig.4C).
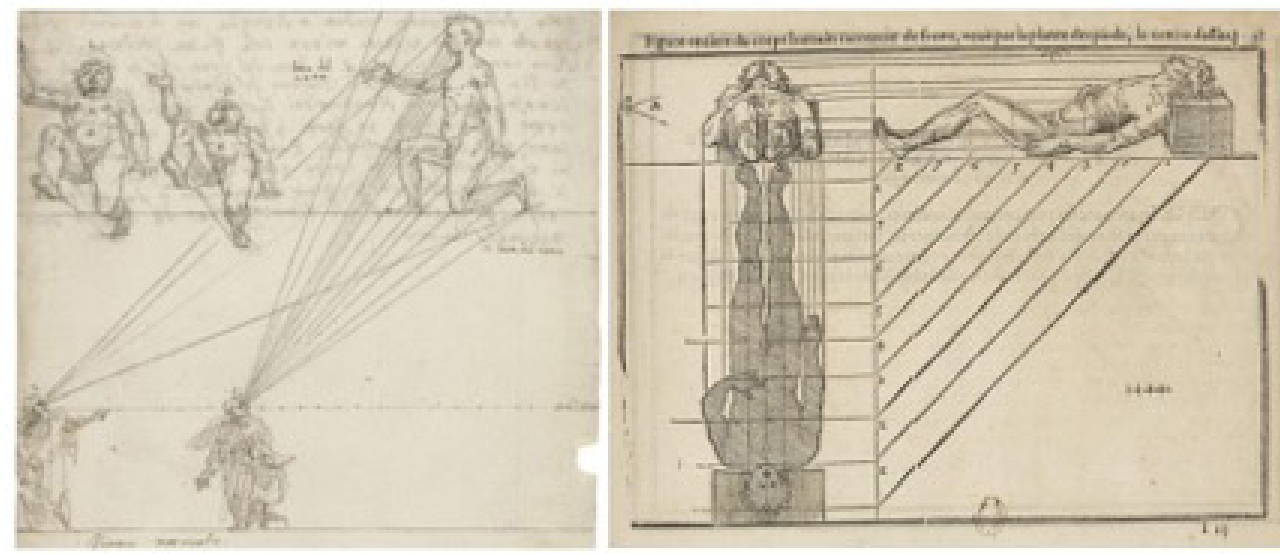

Figura 4A. Prospettiva delle Regole del Disegno, folio 115. Carlo Urbino. (Disponible en The Morgan Library http://www.themorgan.org/collections/works/codex/huygens/page/155). Figura 4B. Livre de Pourtraicture. folio 35. (Extraída del tratado original). Figura 4C. De_symmetria, folio 22r. (Extraída del tratado original). 
Todos estos Tratados citados llegaron con retraso a los talleres a excepción de los manuscritos en latín y vulgar de Alberti y en todo caso de Piero. Sin embargo esto no fue un obstáculo para que los grandes maestros, que en aquella época representaban generalmente sus personajes en posiciones paralelas al soporte en el que pintaban, empezaran a incluir en él y poco a poco, figuras en discretos escorzos.

La posición del soporte sobre el que los artistas trabajaban, tuvo una gran importancia en el resultado de la representación, no era lo mismo el lienzo que el muro, donde las figuras tendrían otro tamaño y podían ser vistas desde distintas posiciones. Resultaba evidente que tampoco se llevarían los mismos planteamientos a las figuras que ocupasen el techo o el espacio de transición entre éste y el muro.

\section{La figura en escorzo, pintada sobre un soporte vertical}

El escorzo apareció inicialmente situando las figuras "tumbadas" sobre el plano horizontal que se representaba. Estos primeros pasos fueron dados por pintores que a su vez dominaban la perspectiva.

Así procedió Paolo Uccello (1397-1475) cuando pintó al temple sobre tabla, "La batalla de San Romano" librada entre Florencia y Siena en 1432.

En la tabla de la National Gallery de este conocido tríptico realizado entre 1438 y 1440 y hoy repartido entre Londres, el Louvre de París, y la Galería de los Uffizi en Florencia, observamos un guerrero en escorzo tumbado en el suelo y situado en la misma dirección que algunas de las lanzas también en tierra (Fig.5A).

Uccello quiso potenciar la sensación espacial de la batalla, imponiendo con el guerrero y las lanzas, la dirección en profundidad representada por el punto de concurrencia de las perpendiculares al cuadro en una perspectiva central. Los caballos en escorzo contribuían también a este propósito.

Parecidos recursos empezaron a ser utilizados por los artistas más dotados. Ya no bastaba con situar un personaje detrás de otro para introducir la profundidad en la escena, en un momento en el que se dibujaban en correcta perspectiva, objetos y elementos constructivos. Parecía necesario introducir también el escorzo en la figura humana para realzar esa tercera dimensión, tan buscada en aquellos momentos. Sin embargo, los primeros pasos, no estuvieron exentos de errores. En esta obra, el guerrero, no parece tener las dimensiones adecuadas.

Años más tarde, en 1457, un joven pintor, Andrea Mantegna (1431-1506) en la capilla Ovetari, de la iglesia de los Eremitani de Padua, representó el traslado de los restos de San Cristóbal. Un colosal cuerpo arrastrado y presentado en un atrevido escorzo, en sintonía con un escenario arquitectónico que se aleja en una perspectiva central. El tamaño indeterminado de San Cristobal no permite establecer referencias que pudieran indicar su correcto dibujo. (Fig.5B).

Mantegna, dieciocho años después, pintó un espectacular "Cristo muerto" hoy en la pinacoteca de Breda en Milán (Fig.5C). También nos dejó un valioso ejemplo en la basílica de San Zenón de Verona, en la Predela situada, a la izquierda, en el retablo del mismo nombre, y hoy en el museo de Tours. Pintada en 1460, al temple sobre tabla, presenta figuras tumbadas y escorzadas muy logradas, que también sirven de ejemplo en esta evolución (Fig.5D). 
Pero la representación del escorzo pronto salto de las figuras "tumbadas" sobre el suelo, al espacio, con el dibujo de ángeles y santos.

Un ejemplo de ello viene de la mano del pintor Luca Signorelli (1445-1523), un aventajado discípulo de Piero, que participó en la decoración de la Capilla Sixtina y que años después realizó los frescos de la capilla de San Brizio en la catedral de Orvieto. Entre 1499 y 1504 pintó numerosas escenas en muros y bóvedas inspiradas en La Divina Comedia de Dante.

En el fresco del muro superior izquierdo de la capilla, en el que se representa " $\mathrm{La}$ predicazione dell'Anticristo", aparecen dos figuras que rompen con la frontalidad en las tres direcciones del espacio. El arcángel San Miguel, que desciende velozmente derribando al falso profeta en su etapa final, y éste, dibujado en un llamativo escorzo tridimensional en el que cuerpo y extremidades se reducen conforme se alejan, en sintonía con un conjunto de rayos convergentes que contribuyen a realzar el efecto buscado (Fig.5E).

Pero además en este fresco abundan los ejemplos bien resueltos de escorzos situados sobre el plano del suelo. Signorelli fue capaz de crear al menos dos grupos con ellos, uno que se presenta en el borde del marco inferior a la izquierda de la composición junto con su autorretrato, mirando al espectador, y el otro, en un segundo plano detrás del anterior.

La monumental arquitectura que por ser de grandes dimensiones, podría quitar protagonismo al tema principal, permanece sin embargo en un segundo plano, y su correcta perspectiva ayuda a ampliar el terreno donde se sitúan las figuras. Allí tienen cabida estos corros de personajes presentados por grupos y que sin embargo, pese a ser numerosos, parecen distar entre si y estar bien distribuidos en el plano horizontal.

Muchos otros ejemplos de figuras en escorzo en el espacio irán apareciendo en la pintura sobre cualquier soporte vertical, hasta convertirse en imprescindibles. A su vez, nuevas consideraciones surgieron entre los fresquistas, al pintar sobre superficies cada vez de mayores dimensiones. La posición que ocupaba cada escena y figura en el muro, respecto a un posible espectador que debería de contemplar el conjunto sin deformaciones, condicionaba cualquier trazado.

Sin embargo, pasaron varias décadas, para que surgiera algún texto que abordara estos temas.

Uno de los artistas que dejó por escrito sus conocimientos en torno a esta problemática fue de nuevo Lomazzo, el mismo que trazo el hilo conductor del término "quadratura".

Lomazzo difunde sus conocimientos porque consideraba muy importante que los artistas se ocuparan no solo de la práctica, sino también de la formación que pudieran adquirir con la lectura.

En este sentido sucede a Gaurico, quizás porque conoció el texto de éste: De Sculptura, donde al señalar las cualidades que debe de tener el escultor, afirma: “... en primer lugar desearía que fuera lo más instruido posible en todas las artes y un perfecto hombre de letras, conocedor de innumerables hechos, leyendas e historias." (Gaurico 1989: 64). 
Lomazzo en su Trattato dell'arte de 1584, ya citado, estudió en qué situaciones posibles se encuentra la figura, al relacionarla con la posición del espectador respecto del plano de la pintura.

Nos fijamos en el Libro $\mathrm{V}$ dedicado a la perspectiva, concretamente en los capítulos X, XI y XII a los que llama Anoptica, Ottica y Catoptica respectivamente. En la figura que se presenta (Fig.5F), y que procede de la traducción inglesa de 1598, Lomazzo fija la línea del horizonte y representa dos prismas uno frontal y otro escorzado ocupando las tres posiciones en el espacio citadas. La Anoptica o vista desde abajo, la Ottica o vista a nivel (el c.d.g del prisma) y Catoptica o vista desde arriba. En los capítulos que van del X al XII analiza la vista frontal y en escorzo de cada una de ellas. (Lomazzo.1598:204).

Es interesante observar que todos los prismas se presentan con caras paralelas y perpendiculares al plano de proyección o plano del cuadro, esto obliga a que las aristas en profundidad fuguen en el punto principal situado sobre la línea del horizonte y también a que las aristas verticales se vean como tales.

Un ejemplo de trazado en posición Anoptica, es el fresco que ocupa el muro lateral izquierdo de la Capilla Foppa en la Iglesia de San Marco de Milán, obra de 1574 realizada por el propio Lomazzo, en la que escenifica la "Caída de Simón Mago" con un escorzo difícil de mejorar. (Fig.5G).

En esta obra, los elementos verticales, los dibuja como son, siguiendo sus propias enseñanzas. Es la posición Anóptica, en la que toda la escena pintada está por encima de la línea del horizonte. Cuando contemplamos el fresco, levantamos la cabeza y perdemos el paralelismo entre nuestra retina y el muro, observando cómo las líneas verticales y las figuras erguidas parecen converger en un tercer punto de fuga situado por encima de la escena pintada. En definitiva, lo que el artista representa en una correcta perspectiva, sin ningún punto de fuga vertical, es modificado por nuestra propia mirada, que nos hace creer que participamos de ese espacio pintado 

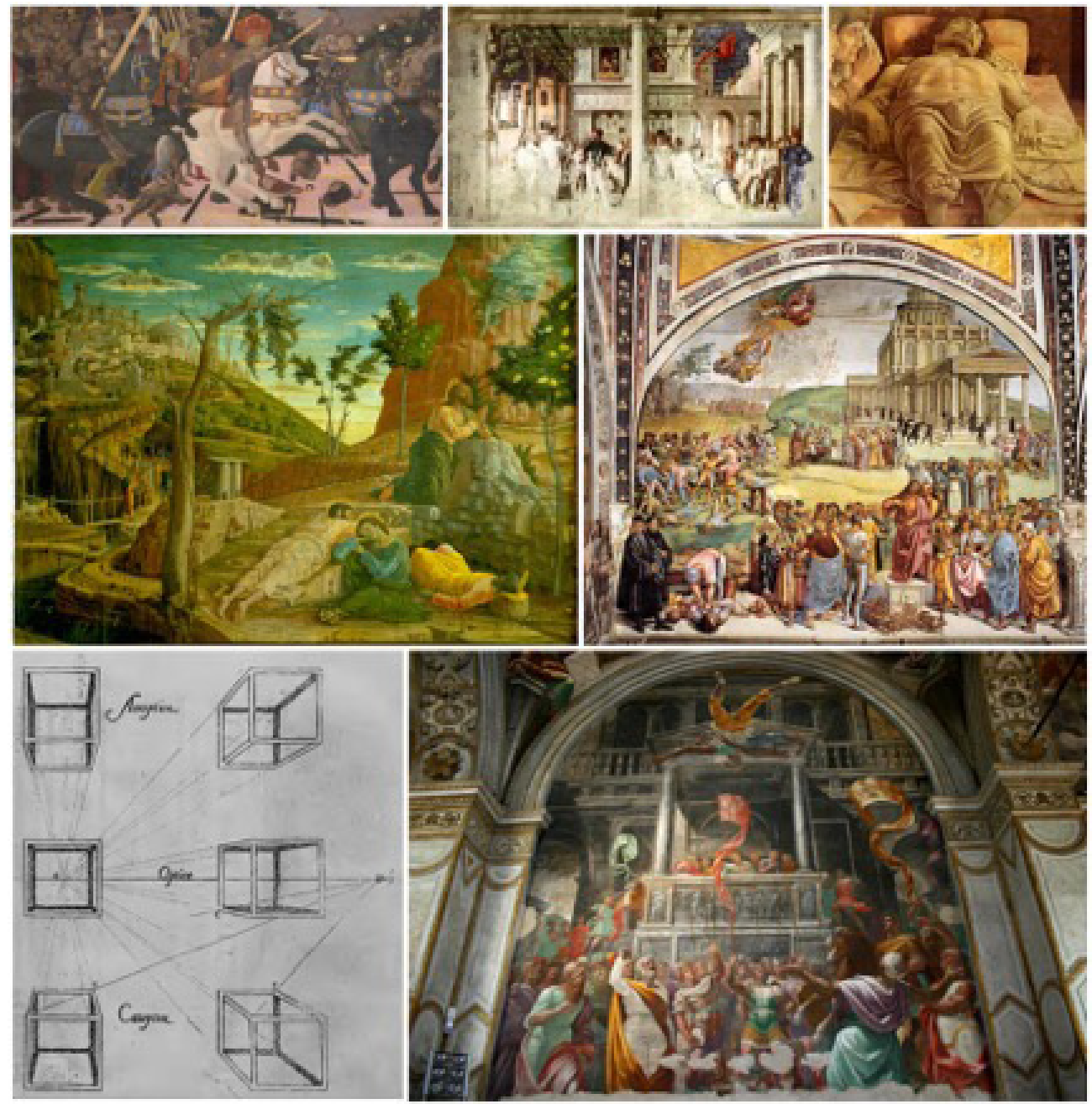

Figura 5A. "La batalla de San Romano". National Gallery (Disponible en http://www.nationalgallery. org.uk/paintings/paolo-uccello-the-battle-of-san-romano). Figura 5B. "San Cristobal", capilla Ovetari, en los Eremitani de Padua. (Disponible en https://upload.wikimedia.org/wikipedia/commons/d/ d4/Ovetari\%2C_san_cristorforo_05-06\%2C_Martirio_e trasporto_del_corpo_decapitato_di san_Cristoforo_di_Andrea_Mantegna.jpg). Figura 5C. "Cristo muerto. Pinacoteca de Breda. Milán. (Disponible en https://es.wikipedia.org/wiki/Andrea_Mantegna\#/media/File:Andrea Mantegna_034.jpg).Figura 5D. "Predela". Retablo de San Zenón. Museo de Tours. (Disponible en pág. Web del Museo http://www.mba.tours.fr/index.php?idtf=5214\&TPL_CODE=TPL

COLLECTIONPIECE\&PIECENUM=38). Figura 5E. La predicazione dell'Anticristo. Capilla $\overline{\text { de }}$ San Brizio.Catedral de Orvieto.(Disponible en https://upload.wikimedia.org/wikipedia/commons/1/15/ Fra_angelico_luca_signorelli_orvieto.jpg). Figura 5F. "Trattato dell'arte della pittura, scoltura, et architettura".folio 204. (Extraída del tratado original). Figura 5G "Caída de Simón Mago" Capilla Foppa. San Marco. Milán. (Disponible en https://upload.wikimedia.org/wikipedia/commons/0/00/ IMG_8384_-_Milano_-_San_Marco_-_Cappella_Foppa_-_Foto_Giovanni_Dall\%27Orto_14Apr-2007.jpg). 


\section{La figura en escorzo, pintada sobre la superficie de transición entre el muro y el techo}

Uno de los escasos manuscritos que se pudo anticipar a las necesidades que en la práctica tenía que resolver el artista y muy especialmente el experto en pintura mural, fue el Tratado Della Pittura, redactado (según los últimos estudios) entre 1487 y 1514 por Leonardo da Vinci. (Da Vinci.1651).

$\mathrm{Su}$ lectura orientaba a quienes trabajaban en los grandes espacios, donde frecuentemente se encontraban con la necesidad de pintar en la superficie de transición entre el plano vertical (muro) y el horizontal (techo). Esta superficie en continuidad con el muro, se resolvía con frecuencia mediante una bóveda esquifada, plana o de arista, que iba a permitir que la escena pintada en el techo se desarrollara o ampliara sobre ella sin enlazar necesariamente con el plano vertical, donde en todo caso, se representaban otras escenas diferentes, separadas de la bóveda por cualquier tipo de moldura o cornisa.

Leonardo expone -en la sección CCCI- de su manuscrito, como pintar sobre una pared (bóveda), una figura que tiene el doble de altura que ella:

...En la pared recta, que está detrás, se dibujara la figura del tamaño que se quiera de perfil, y se tirarán las líneas de los puntos principales al punto $F$; y siguiendo los puntos en que cortan la superficie de la bóveda N. R., que es semejante a la pared, se irá tanteando la figura; y las intersecciones señalarán todas las dimensiones de ella, cuya forma se irá siguiendo, porque la figura misma se disminuye conforme se atrasa. (Da Vinci.1985:134-5).

Añadiendo que la figura que tratamos de dibujar, colocada en la posición descrita, quedaría representada sobre la superficie, como intersección de los rayos visuales con la bóveda. (Fig.6A)

En esta ocasión el estudio teórico se adelanta a una de las obras más representativas de este modo de pintar, la llamada Galería de Cupido y Psique, la loggia de ingreso a Villa Farnesina (Roma), propiedad de Agustino Chigi (1466-1520), un banquero y mecenas sienes, amigo de Rafael (1483-1520), a quien encargaría su decoración.

Es en este gran espacio arquitectónico de transición entre el espacio exterior y el interior del palacio donde encontramos uno de los más significativos ejemplos de figuras en escorzo pintadas sobre superficies curvas.

En él, Rafael y su taller, desarrollaron, durante los años 1517-18, las escenas mitológicas de la boda entre Cupido y Psique. Rafael preparó todos los cartones para la ejecución de los frescos, en la que según Vasari (1511-1574) participó también. (Vasari.1998:359).

Se repartieron el trabajo sus prestigiosos ayudantes. La mayor parte de las figuras fueron pintadas por Giulio Romano (1499-1546) y Francesco Penni (1488-1528), mientras que los festones de guirnaldas que dividen el espacio, aprovechando encuentros y aristas, los realizaría Giovanni da Udine (1487-1564) dejando que entre festones y figuras se viera el cielo azul sobre el que gravitan las escenas, como si de una pérgola se tratase. 
En los diez apoyos de la bóveda sobre las pilastras, es donde Rafael describe parte de la historia y las figuras en escorzo que nos interesan.

Un bello ejemplo es la escena de Psique trasladada ante Venus por Cupido y otros "putti". El conjunto parece flotar en el espacio interior desde donde la contemplamos. Las figuras en escorzo desafían la curvatura del soporte, al lograr la sensación de que piernas y pies se sitúan fuera del arranque de la bóveda en la que están pintados. (Fig.6B).

A la "loggia" de ingreso en Villa Farnesina, le siguieron otros muchos ejemplos, pues los fresquistas continuaron trabajando en estos soportes curvos durante años y por ello los estudiosos de la geometría profundizaron en las pautas establecidas por Leonardo. En 1582 aparecería en Bolonia, el tratado de Jacobbo Barozzi (Il Vignola) (1507-1573) Le due regole della prospettiua prattica, publicado y comentado por el clérigo, boloñés Egnazio Danti (1536-1586), en el que se volvía a considerar el mismo tema. En el capítulo ocho de la segunda parte y dentro del apartado dedicado "al modo de hacer la Perspectiva en techos planos y bóvedas que se ven de abajo a arriba", se describe "el modo de pintar la perspectiva en la bóveda", añadiendo que: "Esta es la absolutamente más difícil operación, que al perspectivo se le puede ofrecer..." (Vignola.1611: 89).

Danti, empleó el mismo método de Leonardo, obteniendo sobre el arranque de la bóveda la perspectiva de las tres columnas que dibuja. Al situarlas a diferentes distancias del espectador, mostró como la altura se reduce en su proyección sobre la bóveda, al alejarse del hipotético punto de vista. (Fig.6C).

\section{La figura en escorzo, pintada sobre el techo plano, o la superficie abovedada}

Si en la galería de la Farnesina observamos la superficie plana del techo, nos encontramos con los temas principales que dan nombre a la loggia. Allí, encerradas por la fingida pérgola de festones, los artistas del taller de Rafael, pintaron lo que simulan ser dos tapices, el "Concilio de los dioses", y el "Banquete nupcial", escenas ambas, que deben ser contempladas como si adoptaran una posición vertical.

Lo que parecen "cuadros" en la superficie del techo, -en este caso tapices-, eran los llamados "cuadros trasladados" en los que podían aparecer figuras escorzadas y escenarios en perspectiva. Durante años y hasta que las espectaculares composiciones del barroco se imponen, el quadri riportati fue la solución de muchas de las grandes decoraciones realizadas en villas, palacios e iglesias, como hemos visto en el salón Cambiaso, anteriormente comentado. Los artistas veían en este procedimiento una buena solución para las grandes bóvedas y techos, pues el marco fingido inducía al espectador a centrar su posición para una correcta percepción de la obra, evitando así las deformaciones que produce su contemplación desde otros puntos de vista. (Fig.6D)

Sin embargo hubo un artista que se atrevió a dar una primera solución diferente a una enorme superficie abovedada: Miguel Angel Buonarroti (1475-1564)

Cinco años antes de iniciar Rafael los frescos de la loggia citada, se daba por concluida la obra que protagonizó el verdadero salto en la representación de la figura humana, la decoración que más ha trascendido en la pintura de techos y bóvedas: la Capilla Sixtina del Vaticano. 
Miguel Ángel, desde 1508 hasta 1512 trabajó pintando un insuperable ejemplo de escorzos, pensados para que pudieran ser apreciados a más de veinte metros de altura, en una colosal bóveda de cañón, muy rebajada, sobre la que en lugar de utilizar el quadri riportati fingió una estructura arquitectónica para ordenar toda la composición.

Para ello, a partir de los arcos de arranque de las ocho enjutas que cierran los lunetos, situadas a ambos lados de la capilla, todo lo que pintaría son elementos fingidos sobre la bóveda, incluyendo éstas y las cuatro pechinas de las esquinas. Este rico escenario arquitectónico de, basas, fustes con estatuas, capiteles, cornisas, y arcos fajones, enriquece a la vez que sirve para enmarcar las escenas y sus logradas figuras.

Miguel Ángel divide la bóveda en sentido longitudinal en tres partes, dos laterales y una central. Ello le servirá para orientar las figuras. La superficie lateral o arranque de la bóveda en cada lado, debe ser vista en relación con el muro en el que apoya. Es entonces y en la parte más alta, donde utilizando la cornisa, sienta otras figuras que coronan y dan fin a esa orientación en cada lado.

Estas superficies curvas de ambos lados, que hemos llamado de arranque de la bóveda, para diferenciarlas de la zona central, tienen figuras de mayor tamaño que aquella, quizás para conseguir el efecto de una mayor altura en el centro de la bóveda como contraste de tamaños. Todas ellas representan a Profetas y Sibilas sentados en sus tronos en diversas posturas o escorzos.

Cada escena está representada mediante una perspectiva frontal, pues al contemplarla nos parece estar viendo un muro vertical en el que cada Profeta se sitúa a la altura de nuestros ojos, lo que Lomazzo llamaría, años más tarde, vista "Ottica". Basta con observar que tanto vemos el empeine de los pies, como las molduras de la cornisa superior que enmarca la escena.

Las nueve historias del Génesis del paño central están separadas por arcos fajones fingidos, y todas ellas tienen el mismo tratamiento que se ha descrito para las superficies laterales, con dos diferencias, la primera que son de menor tamaño, quizás por las razones antes comentadas, y la segunda, que al tratarse del centro de la bóveda, las escenas con sus figuras ya no están situadas en continuidad con los arranques y son orientadas para ser vistas al avanzar hacia el muro del "Juicio Final".

Miguel Ángel resolvió con determinación el tratamiento óptico de esta gran superficie. No quiso ofrecer un único punto de vista concreto para contemplar la bóveda, dado su gran tamaño, y decidió presentar todos los escorzos desde un punto de vista ideal centrado en cada escena como si cada una fuera un lienzo o mural de pequeñas dimensiones. De esta manera estaba seguro de que siempre, sus figuras se verían correctamente.

La obra fue completada veinticinco años más tarde con "El juicio final" (153741), un impactante fresco que ocupa la totalidad del muro tras el altar. En él, Miguel Ángel quiso agrupar las figuras en bandas horizontales separadas por el cielo azul como fondo y en correspondencia con el orden de los muros laterales. La escena se distribuyó en cuatro regiones, siendo la inferior la que dedica a la Tierra. En un enorme cielo todo él lleno de vida y acción, que podríamos decir que alcanza la vertical del observador, se sitúan las figuras más representativas.

El conjunto global de la obra, no responde a un criterio óptico euclidiano, sin embargo parece que Miguel Ángel sí quiso dar unidad a cada región o banda 
horizontal del muro, pues allí los tamaños de las figuras si presentan relación con dichos criterios.

En cada una de ellas, los escorzos están en armonía con su entorno inmediato, pero no con los demás. En la que corresponde a la figura de Cristo, una multitud a ambos lados se ordena espacialmente en profundidad con los efectos de la perspectiva.

Las dimensiones de las figuras, dependen en la práctica de la región en la que se sitúan, diferenciando con ello las escenas, y estableciendo un orden jerárquico, compositivo y secuencial. Vemos como Miguel Ángel amplía el tamaño de las que se sitúan en la escena de Cristo, consiguiendo que centremos nuestra atención en ellas, allí donde el Hijo de Dios hace justicia y separa a los justos de los pecadores.

Hay figuras de todas las edades, en todo tipo de posiciones, y con todo tipo de expresiones, ya sea en la tierra, ya sea en el cielo, siendo todo el mural en definitiva una exhibición de escorzos, y aunque no supuso un ejemplo de aplicación de las leyes geométricas de la perspectiva al conjunto, si lo fue, en cada figura considerada de manera aislada, como quizás Miguel Ángel la quería presentar, evidenciando así la idea, de que es individualmente como el hombre respondería ante Dios de su actuación en esta vida. (Fig.6E).

Otros pintores, con anterioridad, abrieron nuevos caminos en la pintura mural de techos y bóvedas. Su uso como plano de proyección para representar el escorzo de la figura humana, tuvo representaciones más modestas que sin embargo marcaron la dirección a tomar en muchas de las grandes composiciones murales sobre bóvedas y cúpulas en épocas posteriores.

La más significativa la había aportado tiempo atrás, Andrea Mantegna abriendo un óculo fingido en el techo de la Cámara de los esposos del Palacio Ducal de Mantua en 1474 .

Mantegna se propuso pintar las figuras de abajo a arriba, tal y como se las "debería de ver" si levantáramos la mirada, y se inventó un óculo, que como tal permitiera ver el cielo como fondo, disponiendo una balaustrada con angelitos dibujados en escorzo y situados fuera de su protección. Todo un ejemplo a seguir que iniciaba la larga evolución de este tipo de pintura que recibe el nombre abreviado de "sotto in su" y que contó con Tratadistas, muy posteriores, como es el caso de Jean Cousin y su Livre de Pourtraicture, ya citado, publicado casi 100 años después y en el que, como hemos visto, enseña a dibujar de abajo a arriba la figura humana (Fig.4B).

Con el óculo, apareció para los fresquistas la posición de un punto de concurrencia para las rectas verticales equiparable al punto $\mathrm{P}$ de la perspectiva central. $\mathrm{Y}$ un punto de distancia para poder medir la altura de las verticales, similar al que con el mismo nombre servía para medir las rectas concurrentes en P. En definitiva, se pudieron asociar las perspectivas de soporte vertical y horizontal. No era difícil pensar en un giro ortogonal del conjunto para poder aplicar los procedimientos de siempre. Es entonces cuando la figura humana alcanzó su más espectacular escorzo. Un modelo a seguir durante siglos. (Fig.6F). 


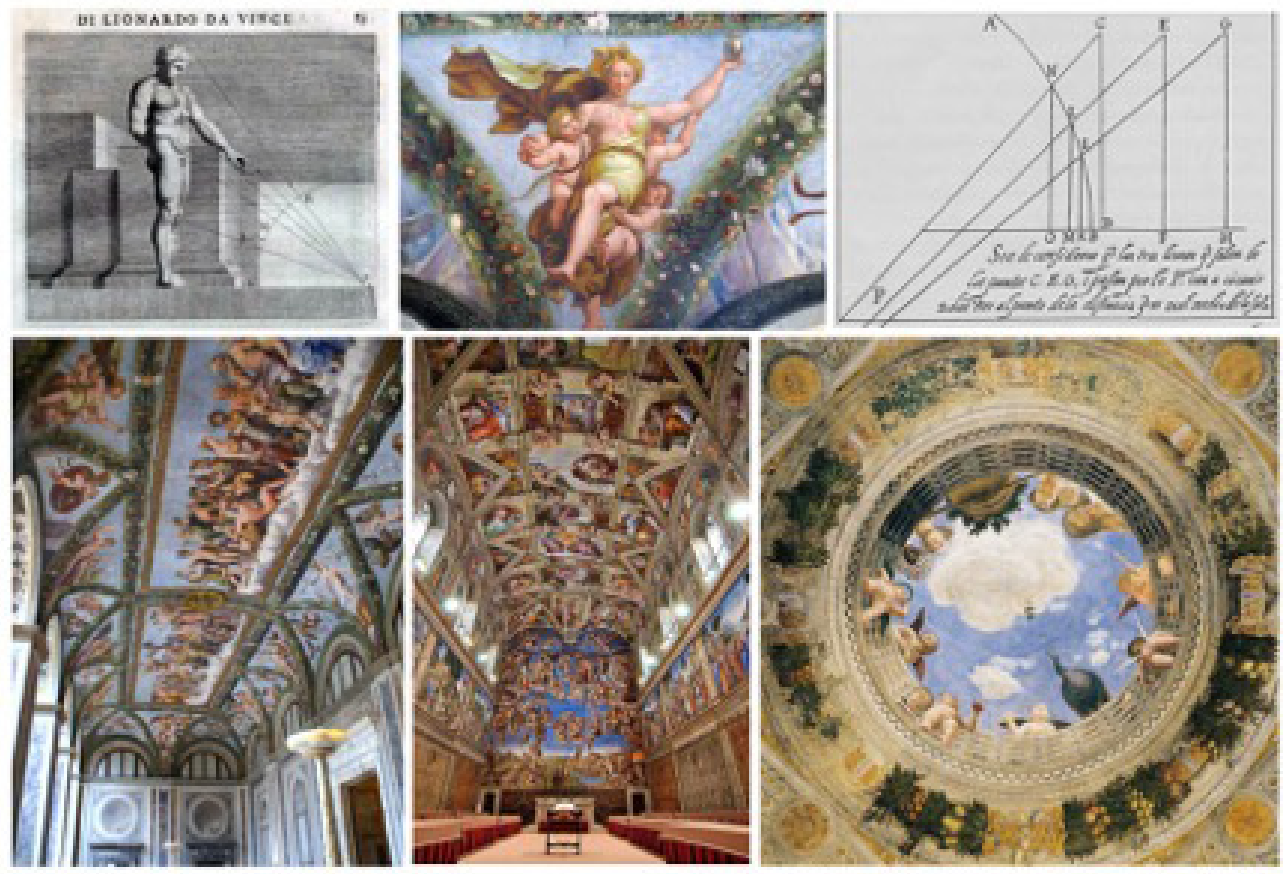

Figura 6A. Della Pittura .Sección CCCI. (Extraída del tratado original). Figura 6B. Psique. "loggia" de Villa Farnesina.Roma. (Fotografía del autor). Figura $6 \mathrm{C}$ Le due regole della prospettiua prattica. Folio 89. (Extraída del tratado original). Figura 6D. Techo de la "loggia" de Villa Farnesina. Roma.

(Fotografía del autor). Figura 6E. Capilla Sixtina del Vaticano. (Página web del Vaticano: http:// mv.vatican.va/4_ES/pages/CSN/CSN_Main.html. Figura 6F. Óculo de la Cámara de los esposos del Palacio Ducal de Mantua (Fotografía del autor).

\section{Referencias}

Alberti, L.B. (1999 [1435]). Los tres libros de la pintura. Madrid: Tecnos Arfe y Villafañe, J. (1773 \{1585]). De varia commensuración para la Esculptura y Architectura. Madrid: Imprenta Miguel Escribano.

Barbaro, D. (1569 [1568]). La pratica della perspettiva Venecia. 1569. Camillo \& Rutilio Borgominieri.

Barozzi da Vignola, J. \& Danti, E. (1682 [1582]). Le due regole della prospettiua prattica. Bolonia: Gioseffo Longhi. G.

Bora, G. (1999) Prospettiva lineare e prospettiva de'perdimenti: un dibattito sullo scorcio del Quattrocento. Paragone, 595, pp. 3-45.

Cousin, J. (1560). Livre de perspective. Paris: Ichan le Royer.

Cousin, J. (1656 [1571]). Livre de pourtraicture. Paris: Chez Guillaume le Be.

Da Vinci, L. (2001 [1508-1518]). Aforismos. Madrid: Espasa Calpe.

Da Vinci, L. (1651 [1487-1514]). Trattato della pittura di Lionardo da Vinci [....] e il trattato della statua di Leon Battista Alberti. Paris: Trichet Du Fresne, Raphaël. Éditeur scientifique. 
Da Vinci, L. (1985 [1487-1514]). El Tratado de la Pintura de Leonardo da Vinci, y los tres libros que sobre el mismo arte escribió León Bautista Alberti. Edición de la traducción de Diego Antonio Rejón de Silva de $1784 . \quad$ Murcia: Caja Murcia.

Durero, A, (2000 [1525-1538]).Underweysung der Messung, Madrid:Akal.

Durero, A, (1557 [1528]). De symmetria partium in rectis formis humanorum corporum. Paris:Caroli Perier.

Gaurico, P (1989 [1504\}). Sobre la escultura. Madrid: Akal

Honnecourt, V. (1991 [s.XIII]) Cuaderno. Madrid: Akal

Lomazzo, G. P. (1590 [1571]). Idea del tempio della pittura. Milán: P.G.Pontio.

Lomazzo, G. P. (1585 [1584]). Trattato dell'arte della pittura, scoltura, et architettura. Milán:P.G.Pontio.

Lomazzo, G. P. (1598 [1584]). Trattato dell'arte della pittura, scoltura, et architettura. Oxford: Ioseph Barnes.

Della Francesca, P (1984 [1474]). De Prospectiva pingendi. Edizione critica a cura di G. Nicco

Fasola. Florencia: Casa Editrice le lettere.

Schön, E. (1540). Unnderweissung der Proportzion. Nuremberg: Editor desconocido.

Urbino, C (1560-1570). Códice Huygens. Nueva York. Morgan Library

Vasari. G. (1998[1550]). La vida de los más excelentes arquitectos, pintores y escultores italianos. Madrid: Tecnos.

Villanueva L.(1996). Perspectiva lineal. Su relación con la fotografía. Barcelona: Ediciones U.P.C.

Vitruvio M.L. (1980 [41]) Los diez libros de arquitectura. Barcelona: Editorial Iberia.

\section{Notas}

1. Autores como Vagnetti Luigi aplican la expresión "Construcción legítima" a este método, otros lo hacen a la descripción del procedimiento que Alberti hace en su obra "de la pintura" 1435. A este respecto véase (Villanueva, 1996:113). Hoy en numerosos libros de Perspectiva aparece como "Método Directo".

2. Erhard Schön, fue un artista muy prolífico, ilustró numerosos libros, y su interés por la perspectiva le llevó a especializarse en figuras anamórficas, donde la imagen secreta se escondía dentro de la imagen que se presentaba y solo hacía falta encontrar el punto de vista elegido por su autor para desvelar una nueva imagen, en general sorprendente. Es ésta su faceta como artista más conocida. 